\title{
Local fishermen's perceptions of the usefulness of artificial reef ecosystem services in Portugal
}

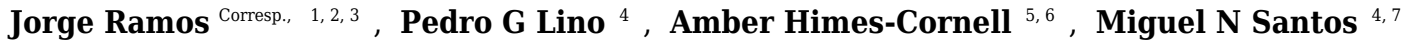 \\ 1 IPMA - Portuguese Institute for the Ocean and Atmosphere, I.P., Lisbon, Portugal \\ 2 MARE - Marine and Environmental Sciences Centre, ESTM, Instituto Politécnico de Leiria, Peniche, Portugal \\ 3 CinTurs/CIEO - Research Centre for Spatial and Organizational Dynamics, Universidade do Algarve, Faro, Portugal \\ 4 IPMA - Portuguese Institute for the Ocean and Atmosphere, I.P., Olhão, Portugal \\ 5 IUEM - European Institute of Marine Sciences, Université de Brest, Plouzané, France \\ 6 Fisheries Policy, Economics and Institutions Branch, Fisheries and Aquaculture Policy and Resources Division, Food and Agriculture Organisation of the \\ United Nations (FAO), Rome, Italy \\ 7 ICCAT - International Commission for the Conservation of Atlantic Tunas, Madrid, Spain \\ Corresponding Author: Jorge Ramos \\ Email address: jhramos@ualg.pt
}

Proponents of artificial reef (AR) deployment are often motivated by the usefulness of such structures. The usefulness of ARs is related to their capability of providing ecosystem services/additional functions. We present two distinct Portuguese AR case studies: 1) The Nazaré reef off the central coast of Portugal and 2) the Oura reef off the Algarve coast. Semi-structured interviews were conducted with local fishermen in the fishing towns of Nazaré and Quarteira pre- and post-AR deployment. The main focus of the interviews was to understand fishermen's perception of AR usefulness (or lack thereof) in terms of nine ecosystem services/additional functions potentially provided by the ARs. We tested the null hypothesis that ARs do not provide additional ecosystem services/additional functions. When queried pre-AR deployment, fishermen indicated that ARs are most likely to provide three ecosystem services: "habitat and refuge," "biodiversity preservation" and "food production". Fishermen had similar perceptions post-deployment. For the Nazaré reef, fishermen tended to have a positive or neutral perception of ecosystem services/additional functions being provided by ARs. For the Oura reef, fishermen tended to have a mostly neutral perception of AR ecosystem services; however, there were also some positive and other negative perceptions. It was difficult for stakeholders to conceptualize some of the ecosystem services/additional functions provided by ARs prior to actively using them. As a result, some stakeholders changed their perception of the ecosystem services/additional functions after using the structures. These results indicate that stakeholders likely need to perceive ARs as useful in order for them to provide their support for AR installation. Likewise, their support is often needed to justify the use of public funds to install ARs, therefore making it imperative for resource managers to undertake similar interviews with 
fishermen when considering the use of ARs in other areas. 


\section{Local fishermen's perceptions of the usefulness of artificial reef ecosystem services in 2 Portugal}

3

4 Jorge Ramos ${ }^{1,4,6^{*}}$, Pedro G. Lino ${ }^{2}$, Amber Himes-Cornell ${ }^{3,7}$, and Miguel N. Santos ${ }^{2,5}$

$5{ }^{1}$ IPMA - Portuguese Institute for the Ocean and Atmosphere, I.P., R. Alfredo Magalhães Ramalho, 6, 1495-006 Lisbon, 6 PORTUGAL

7 2 IPMA - Portuguese Institute for the Ocean and Atmosphere, I.P., Av. 5 de Outubro s/n, 8700-305 Olhão, PORTUGAL

$8{ }^{3}$ IUEM - European Institute of Marine Sciences, Université de Brest, UMR6308, Rue Dumont D’Urville, 29280 Plouzané, 9 FRANCE

10 ${ }^{4}$ MARE - Marine and Environmental Sciences Centre, ESTM - Instituto Politécnico de Leiria, 2520-641 Peniche, PORTUGAL

$11{ }^{5}$ ICCAT - International Commission for the Conservation of Atlantic Tunas, Corazón de Maria, 8, 28002 Madrid, SPAIN

$12{ }^{6}$ CinTurs/CIEO - Research Centre for Spatial and Organizational Dynamics, Universidade do Algarve, 8005-139 Faro, 13 PORTUGAL

$14{ }^{7}$ Food and Agriculture Organisation of the United Nations (FAO), Fisheries Policy, Economics and Institutions Branch, Fisheries 15 and Aquaculture Policy and Resources Division, Rome, 00153, ITALY

17 *Corresponding author. Tel.: +351 289700 500.E-mail address: jhramos@ualg.pt; jormos@gmail.com

19 Running title

20 Perception of artificial reef ecosystem services

\section{Abstract}

23 Proponents of artificial reef (AR) deployment are often motivated by the usefulness of such 24 structures, which is related to the capability of ARs to provide ecosystem services and additional

25 functions. To better understand this, we present two distinct Portuguese AR case studies: 1) The

26 Nazare reef off the central coast of Portugal and 2) the Oura reef off the Algarve coast. Semi- 
27 structured interviews were conducted with local fishermen in the fishing towns of Nazaré and 28 Quarteira pre- and post-AR deployment. The main focus of the interviews was to understand 29 fishermen's perception of AR usefulness (or lack thereof) in terms of nine ecosystem 30 services/additional functions potentially provided by the ARs. We tested the null hypothesis that 31 ARs do not provide additional ecosystem services/additional functions. When queried pre-AR 32 deployment, fishermen indicated that ARs are most likely to provide three ecosystem services: 33 "habitat and refuge," "biodiversity preservation" and "food production". Fishermen had similar 34 perceptions post-deployment. For the Nazaré reef, fishermen tended to have a positive or neutral 35 perception of ecosystem services/additional functions being provided by ARs. For the Oura reef, 36 fishermen tended to have a mostly neutral perception of AR ecosystem services; however, there 37 were also some positive and other negative perceptions. It was difficult for fishermen to conceptualize some of the ecosystem services/additional functions provided by ARs prior to 39 actively using them. As a result, some fishermen changed their perception of the ecosystem 40 services/additional functions after using the structures. These results indicate that fishermen 41 likely need to perceive ARs as useful in order for them to provide their support for AR 42 installation. Likewise, their support is often needed to justify the use of public funds to install 43 ARs, therefore making it imperative for resource managers to undertake similar interviews with 44 fishermen when considering the use of ARs in other areas. 
47 Local fishermen's perceptions of the usefulness of artificial reef ecosystem services in

Portugal

\section{Introduction}

Artificial reefs (ARs) have been used to mitigate coastal fishing pressure, enhance the potential of biodiversity, and enhance fisheries catch (Bohnsack, 1996; Leitão et al., 2009; Santos et al., 2011). ARs can function as an effective resource management measure by diverting fishing effort from overexploited fishing areas, or areas which are environmentally vulnerable, to those which are less heavily exploited or less vulnerable (Bohnsack and Sutherland, 1985; Montemayor, 1991; Kurien, 2003). ARs may contribute to reverse fisheries resource depletion (Watanuki and Gonzales, 2006). Such reefs can also be utilized for diving activities, diverting divers from sensitive natural reefs to man-made structures (Wilhelmsson et al., 1998; Van Treeck and Schuhmacher, 1999; Oh et al., 2008; Polak and Shashar, 2012; Van Treeck and Eisinger, 2012; Oliveira et al., 2015). al., 2008; Tunca et al., 2012). First, AR project proponents need to justify reef advantage and final users need to find reefs useful, otherwise the project may fail (Edwards and Gomez, 2007). For a given AR project, proponents need to gather information to justify deployment, such as benefits that have been documented in existing AR projects, in order to advocate for third party acceptance and obtain funding (Pilkey and Cooper, 2012; Lowry et al., 2014). In this sense, preand post-deployment information is important for empowering and providing justification for

67 future AR projects (Brickhill et al., 2005; Perkol-Finkel and Benayahu, 2005). Unfortunately, 68 studies involving pre- and post-AR deployment are scarce, particularly those dealing with social 69 or economic perspectives (Williams, 2006). Furthermore, although some studies have 
70 demonstrated the socio-economic effects of ARs (Ramos, 2007; Seaman, 2007; Sutton and

71 Busnell, 2007), AR usefulness has been subject to scrutiny (Pratt et al., 2005; Brownell, 2011).

72 For example, Bortone (2006) argues that an AR may enhance species richness, but may not 73 ultimately increase human utility.

74 Interest in the ecosystem services concept has been growing since the late 1990s

75 (Costanza et al., 1997; Sterner, 2003; Costanza et al., 2014; Hackett and Dissanayake, 2014).

76 Many authors have analyzed stakeholder perceptions of the specific ecosystem services provided

77 by various ecosystems (e.g., Lamarque et al., 2011; Chan et al., 2012). Specifically for the case

78 of ARs, studies have shown that stakeholders perceive reef usefulness in various ways depending

79 on whether the ecosystem services that they specifically depend on are enhanced or diminished

80 by the AR (Sosa-López et al., 2005; Chen et al., 2013). Disagreements between stakeholder

81 groups over the usefulness of ARs can present a significant barrier to obtaining public funds for

82 AR deployment (Santos et al., 2008). In order to receive public funds, AR project proponents are

83 often required to show evidence of how socially useful the AR will be (Sawyer, 2001; Ramos et

84 al. 2011a). Given this, one method of supporting the argument for AR deployment is to invest in

85 multi-functional AR projects, where multiple stakeholder groups are likely to perceive and

86 ultimately directly benefit from the AR ( $\mathrm{Ng}$ et al., 2013).

87 This paper investigates the varying perceptions of small-scale fishing communities on the 88 usefulness and potential impacts of ARs in two coastal areas in Portugal. The principal research 89 question we address is: How do fishermen perceive usefulness (or lack thereof) of ARs before 90 and after AR deployment? This question is posed for nine ecosystem services and additional 91 functions that were expected to be provided by the ARs. We first describe the ecosystem services 92 and additional functions that ARs are known to provide in general, followed by a description of 
93 the AR study areas of interest here. We then present the methodology and questionnaire we used

94 to capture stakeholder perceptions of AR usefulness in both locations, the hypotheses we tested

95 with the questionnaire data, and a summary of the results of the interviews conducted for this

96 study. Lastly, we provide a discussion of the ecosystem services and additional functions

97 perceived by fishermen pre- and post-AR deployment in the two case studies, and justification

98 for using public funds to deploy ARs. We also provide an assessment of the limitations of this 99 study and areas of future research.

\section{Artificial reef ecosystem services and other functions}

Marine ecosystems provide a wide range of services that are fundamental to human well-

being and livelihoods, from food production to water filtration and storm protection (de Groot et

al., 2012). The total economic value of AR ecosystem services can be divided into the following categories (Goklany, 2009; Huth and Morgan, 2011; Johns et al., 2013): (1) direct use value (extractive and non-extractive use), (2) indirect use value, and (3) option and non-use value.

Here, we focus on expected AR ecosystem services and additional functions without considering their inherent economic value (Table 1). The list was not intended to be exhaustive, to be used with fishermen in the two case studies presented here.

$111<$ Insert Table 1 here $>$

\section{2.1. Direct use}

114 Food production - Food production is an extractive use associated with artisanal and

115 commercial fishing activities that can be modified through AR deployment. For example, Santos 
116 and Monteiro (2007) investigated the effect of two Algarve AR systems on local fisheries during

117 a 14-year period and found that yields were up to 2.6 times higher at the AR sites than in control 118 areas.

119 Recreation - ARs can provide several opportunities for leisure activities, including 120 surfing (Ten Voorde et al., 2009; Fletcher et al., 2011; Rendle and Rodwell, 2014), diving

121 (Ditton et al., 2002; Musa et al. 2011; Ramos et al. 2011b), spear fishing, and angling from 122 charter boats (Milon, 1989; Chen et al. 2013). Spear fishing and angling are also extractive and 123 may be categorized as "food production." However, we categorize these activities under

124 "recreation" because the principle aim is for personal consumption rather than for commercial 125 sales.

2.2. Indirect use

Biological control - Resource managers can introduce ARs to control undesired organisms through predation, herbivory or any other natural process. In this way, ARs can act as artificial habitats that alter the distribution of species and local biodiversity (Shipp, 1999;

131 Nicoletti et al., 2007; Seaman, 2007). Some species may be lost and others gained (Jacobus and

132 Webb, 2005; Matsuoka et al., 2005). A particular issue related to biological control is the 133 assessment of invader versus native species colonization rates on ARs (Smith, 2010).

134 Nutrient cycling - AR infrastructure provides substrate that contributes to the production 135 of flora and fauna due to high local availability of nutrients in the water column (Perkol-Finkel 136 and Benayahu, 2005; Doyle and Havlick, 2009; Levrel et al., 2012). Falcão et al. (2007)

137 demonstrated that the presence of ARs may increase the deposition of nutrients derived from 138 higher number of marine organisms that will settle there (i.e., higher carrying capacity). This has 
139 a positive impact on the production of fish and other species (Relini et al., 2007).

140 Disturbance regulation - Concrete ARs are increasingly being used as a shoreline

141 protection measure (Bleck and Oumeraci, 2001; Goudas and Katsiaris, 2003). ARs can be

142 installed to minimize coastal damage from storms by absorbing wave energy (Ding et al., 2013).

143 Clauss and Habel (2000) note that ARs may not provide storm protection if they are not

144 strategically located or are too far from the coast. Therefore, if the purpose of an AR is to act as a

145 wave attenuator, they should be deployed close to the shoreline. Conversely, if an AR is meant to

146 increase biological production, then it should be deployed in areas that are not significantly

147 affected by wave disturbance (Ten Voorde et al., 2008; Morang et al., 2014).

148 Habitat and refuge - ARs can be deployed to create habitat and refuges for marine

149 species if adequate depth, temperature, salinity, dissolved oxygen, and the type of materials used 150 are appropriately considered in their construction (Gallaway et al., 1999, Marzinelli et al. 2009).

151 ARs also provide additional surfaces, holes and crevices for settlement of sessile organisms 152 (Clark and Edwards, 1999; Moura et al., 2006, and 2007). Such habitat serves both as a source of

153 food for herbivores (Einbinder et al., 2006) and as a refuge for many species from predators

154 (Simon et al., 2011; Ford and Swearer, 2013). Habitat complexity increases fish assemblages

155 (Charbonnel et al., 2002); therefore, any artificial structure that provides refuge for fish and other 156 marine organisms provide habitat that was unavailable previously (Busch et al., 2012).

$158 \quad$ 2.3. Option use

159 Biodiversity preservation - ARs can be used to improve biodiversity in localized areas.

160 Simberloff and von Holle (1999) contend that biologically disturbed areas have fewer species

161 than undisturbed ones, which means for the case of an AR that an increase in biodiversity may be 
162 evidence of biological success (Allemand et al., 2000; Lamberti and Zanuttigh, 2005). ARs can

163 also be used to reverse declines in commercial species. Due to the difficulty in accessing ARs,

164 ARs not only deter fishermen from fishing in the immediate area or over the area (due to the

165 potential for boat and gear damage), but also decrease fishing pressure in the surrounding areas.

166 This is particularly important during early life stages, where increasing the life expectancy of

167 marine organisms living on an AR acts as insurance for larger catches in the future that can be 168 caught in areas adjacent to the ARs (Goulder and Kennedy, 2011).

\subsection{Additional AR functions}

For the purpose of this study, we consider two additional AR functions beyond ecosystem service provision, namely: reuse of obsolete structures and fishing effort diversion. Both of which have been shown to provide important benefits or impacts. in use, such as scrap materials in combination with reinforced concrete (Bell et al., 1989; Gu, 2005). However, this has been criticized and considered to be ocean dumping that is being done in the vain of fish habitat enhancement (MacDonald, 1999; Chojnacki, 2000). For example, in purposefully sunken in order to provide additional diving spots for recreational use (Ramos et al., 2006; Santos et al., 2011).

Fishing effort diversion - ARs can function as an effective resource management measure to reverse fisheries resources depletion by diverting fishing effort from overexploited

183 fishing areas, or areas which are environmentally vulnerable, to those which are less heavily 184 exploited or less vulnerable (Bohnsack and Sutherland, 1985; Montemayor, 1991; Watanuki and 
185 Gonzales, 2006; Kurien, 2003). ARs can also be utilized to manage diving activities, diverting

186 divers from sensitive natural reefs to man-made structures (Wilhelmsson et al., 1998; Van

187 Treeck and Schuhmacher, 1999; Oh et al., 2008; Polak and Shashar, 2012; Van Treeck and

188 Eisinger, 2012; Oliveira et al., 2015).

189

190 3. Material and methods

$191 \quad$ 3.1. Study area

192 This study focuses on AR deployment case studies located off the coast of Nazaré (Fig.

193 1A; central coast of Portugal) and Oura (Fig. 1B; Algarve, southern Portugal) (Fig. 1). In both

194 case studies, the ARs were deployed between 10 and 40 meters depth, but in areas with very 195 different bottom topography (Fig. 2).

$<$ Insert Fig. 1 about here $>$

198

199

The two case study AR sites have very different geographic profiles (Fig. 2), and can be summarized as follows.

Nazaré artificial reef - The water off Nazaré is home to a diverse assemblage of fish species, which benefits small-scale fishermen that are able to catch fish species that normally 203 inhabit deep water closer to the coastline. The continental shelf extends out from the coast for approximately 2,000 meters and then drops off sharply into a canyon (Fig. 2A and 2B). The 205 central coast of Portugal is subject to harsher weather and more frequent physical disturbance than the southern coast, which in turn affects the ability of coastal human activities to operate 207 (Tyler et al., 2009; Lynn, 2013). The success of previous AR projects in southern Portugal 
208 (Santos and Monteiro, 2007) motivated the development of the Nazare AR project to improve

209 fishermen safety during rougher weather by facilitating the access to a fishing site closer to

210 shore. An AR project was commissioned by the local council in consortium with technical

211 experts from Portuguese fisheries and hydrography research institutes and deployed in 2010. The

212 Nazaré AR covers an area of approximately $3 \mathrm{~km}^{2}$.

213 Oura artificial reef - Adjacent to the Oura coastline, the inner continental shelf extends

214 for over 6,000 meters from the coast (Fig. 2C and 2D). In the early 1990s, two pilot ARs were

215 deployed in southern Portugal and showed increased catches (Santos and Monteiro, 1997, 1998).

216 Following the positive results of these pilot ARs in southern Portugal, the Oura AR was

217 deployed during the second phase of a large effort to deploy ARs across the Algarve coast

218 (Santos and Monteiro, 2007). The Oura AR was deployed in 2003 next to the Vilamoura AR

219 (deployed in 1998), covering an area of approximately $6 \mathrm{~km}^{2}$ (Ramos and Santos, 2015). The AR

220 was primarily deployed provide a new fishing opportunity to the community of small-scale

221 fishermen in the Algarve.

222

$223<$ Insert Fig. 2 about here $>$

224

225

3.2. Data collection

226

In order to assess fishermen perceptions of AR usefulness in the two case studies, we 227 developed a questionnaire focused on stakeholder expectations and perceptions of AR ecosystem services and additional functions (Figure 3). We deemed it necessary to better understand the advantage that potential AR users expect from the structures both before deployment (preusers of these ARs are small-scale fishermen and dive operators; however, the main focus of the 
232 AR deployments in both locations was to promote fisheries. Since our main aim was to better

233 understand fishermen's perceptions, diving operators were not considered in this study.

234 Therefore, the potential survey population for this questionnaire included all fishermen who

235 participate in fisheries that are generally prosecuted adjacent to the ARs.

236

$237<$ Insert Fig. 3 about here $>$

238

239

240

expectations for AR benefits pre-deployment and 2) fishermen's perceptions of actual benefits obtained post-AR deployment. These data were then used to test the model's hypotheses (see

Section 3.5). Pre- and post-deployment primary data were collected through the implementation of semi-structured questionnaire-based interviews with fishermen in each case study location.

\subsection{Pre-AR deployment questionnaire}

A pre-AR deployment questionnaire $\left(\mathrm{Q}_{\mathrm{t} 1}\right)$ was implemented with the aim of better understanding what ecosystem services fishermen believe AR could provide (Table 2). The questionnaire was implemented through face to face interviews in situ at the fishing ports in April 2003 in Quarteira and October 2008 in Nazaré. The questionnaire included demographic questions on ecosystem services and additional functions.

252 
256 of marine resources (Himes, 2007). Having the above in mind, questions were designed to

257 collect fishermen expectations of seven ecosystem services and two additional functions. The

258 interviewer provided each respondent with a brief explanation of each ecosystem service and

259 additional function before beginning the questionnaire. The interviewer then asked the

260 respondent to score their perception of how likely they think the AR will provide each ecosystem

261 service and additional function. Respondents were given a 5-point Likert scale as a means to rate

262 their expectations of future ecosystem service and additional function provision: 1 (much less), 2

263 (slightly less), 3 (the same), 4 (slightly more), or 5 (much more) (Allen \& Seaman, 2007; Dawes,

264 2008; Schmidt et al., 2017). For example, a score of 4 indicates that the respondent expected that

265 the presence of the AR would provide for slightly more of a given ecosystem service; a score of

2662 indicates that the respondent expected that the presence of the AR would provide for slightly

267 less of an ecosystem service. "Don't know" answers were rejected. The questions provoked

268 answers based on the respondent's past experience, knowledge and information about future

269 expectations on AR.

270 We defined the survey population by cross-checking the number of vessels found 271 anchored in their respective fishing ports and those recorded in the European fleet register. We 272 compiled secondary data on small-scale fleet sizes in each case study location (CFR, 2016). 273 According to the European fleet register (CFR, 2016), On December, 31 $1^{\text {st }} 2005$, there were a 274 total of 87 fishing vessels registered in the European fleet register by fleet category length C2 $275[6,10]$ and C3 $[10,12]$ in the Nazaré port and 129 fishing vessels in the Quarteira port. Based on 276 this, we determined that an adequate sample size was $20 \%$ of the small-scale vessel skippers 277 ( $\mathrm{N}=17$ in Nazaré and $\mathrm{N}=26$ in Quarteira). We interviewed a total of 58 skippers (Table 3). 
278 Twelve responses were not usable because either the skippers were from a non-eligible fishing

279 vessel segment or any other reason.

280 The interviews were conducted by one researcher and two technicians from the

281 Portuguese Institute for the Ocean and Atmosphere (IPMA). Respondents were selected by

282 contacting fishermen who have demonstrated interest in sharing their opinions about ARs.

283 Fishing community representatives facilitated the process by introducing eligible fishermen to

284 the interviewers. Interviews were conducted in the fisherman's respective port (Quarteira and 285 Nazaré).

286

287

$<$ Insert Table 3 about here $>$

288

289

\subsection{Post-AR deployment questionnaire}

290

A second questionnaire $\left(\mathrm{Q}_{\mathrm{t} 2}\right)$ was implemented five years after AR deployment (May 2008 in Quarteira and September 2015 in Nazaré). The aim of this survey was to gather

fishermen's perceptions of the benefits they received from the AR so that the answers provided in the pre-deployment and post-deployment questionnaires could be compared. Our expectation was that respondents had learned from the experience of fishing in the vicinity of the AR. The post-deployment questionnaire included 5-point Likert scale questions similar to the predeployment questionnaire, with a focus on the ecosystem services that fishermen believe they

297 have actually benefited from (Table 2). For example, a score of 4 indicates that the respondent 298 realized slightly more of a given ecosystem service after the AR was deployed; a score of 2 299 indicates that respondent realized slightly less of a given ecosystem service after the AR was 300 deployed. The results were used to better understand fishermen's attitudes towards AR presence 
301 and acceptability (or refusal) by the fishing community.

302 The post-deployment questionnaire followed the same sampling strategy and

303 implementation methodology as described for the pre-deployment questionnaire. On December,

$30431^{\text {st }} 2015$, there were a total of 94 fishing vessels registered in the Nazaré port Authority and 118

305 fishing vessels in the Quarteira port. We interviewed a total of 49 skippers (Table 3). Three

306 responses were not usable because either the skippers were from a non-eligible fishing vessel

307 segment or any other reason.

308

309 3.5. Hypotheses

310 Since we used the 5-point Likert scale data to score the AR effect and the respondents to

311 each questionnaire were not the same pre- and post-deployment, we cannot assume that the

312 population of the ranking scores given by the respondents is normally distributed. Therefore, for

313 each fishing community, we used the Mann-Whitney U test (also known as Wilcoxon rank-sum

314 test) to test: 1) the null hypothesis that it was equally likely that each of the ecosystem service

315 perception scores given by fishermen would be the same after reef deployment $\left(\mathrm{H}_{0}\right)$, against 2)

316 the alternative hypothesis that each of the ecosystem service perception scores given by

317 fishermen would differ between the pre- and post-deployment questionnaires $\left(\mathrm{H}_{1}\right)$. We used $\mathrm{R}$

318 software version 3.1.3 (R Development Core Team, 2015) to test both hypotheses.

$320 \mathrm{H}_{0}$ : Perception of $\mathrm{x}_{\mathrm{n}}$ pre-deployment $=$ Perception of $\mathrm{x}_{\mathrm{n}}$ post-deployment

$321 \mathrm{H}_{1}$ : Perception of $\mathrm{x}_{\mathrm{n}}$ pre-deployment $\neq$ Perception of $\mathrm{x}_{\mathrm{n}}$ post-deployment

323 where $\mathrm{X}=\mathrm{c}\left(\mathrm{x}_{1}, \mathrm{x}_{2}, \mathrm{x}_{3}, \ldots, \mathrm{x}_{9}\right), \mathrm{X}$ is a set of seven ecosystem services and two additional 
324 functions potentially provided by AR and $x_{n}$ is a given ecosystem service or additional function 325 from $\mathrm{X}$.

326

\section{4. Results}

328 In general, for both case study sites and both time periods, respondents indicated that 329 "habitat and refuge" was the most expected (pre-deployment question) or realized (post330 deployment question) AR ecosystem service, followed closely by "biodiversity preservation" 331 and "food production" (Figure 4). Given the small sample size $(\mathrm{n}=23)$ and non-normal data sets

332 (ordinal variables), we conducted a non-parametric Wilcoxon test for each case study site 333 individually to compare respondents' perceptions of ecosystem service provision pre- and post-

334 AR deployment (Table 4). The Wilcoxon test indicated that for most of the ecosystem services,

335 the median Likert scale scores for expected ecosystem services (pre-deployment) were not 336 similar to the ecosystem services that were actually realized (post-deployment) for either case 337 study $(\mathrm{p}>0.05)$. However, the median likert scores pre- and post-deployment for the additional 338 AR function of "reuse of obsolete structures" was found to be significant for both locations 339 (Oura: $p<0.0005$ and Nazaré: $p<0.05$ ).

$341<$ Insert Fig. 4 about here>

342

343 <Insert Table 4 about here>

In comparing the pre- and post-deployment responses of Nazaré respondents (Figure 4),

346 there is slightly higher variability in responses related to "food production" in the post- 
347 deployment phase, where many respondents did not perceive that the AR had increased "food

348 production" and the scores for "food production" denoted different catch experiences across

349 respondents. The data distribution is less variable for the ecosystem service "recreation" and the

350 additional function "reuse of obsolete structures," indicating that the combined responses have a

351 higher certainty of the effects derived from obsolete structures after reef deployment.

352 The Wilcoxon test shows that Nazaré respondents perceived fewer changes in ecosystem

353 services when doing comparisons before and after reef deployment. Most of before and after data

354 presented similar distributions. Significant differences between pre- and post-deployment

355 responses were only found for "recreation", "biological control" and "reuse of obsolete

356 structures" ( $\mathrm{p}$-value $<0.05$ ), for which median responses showed that respondents' expectations

357 pre-deployment for the ecosystem services that the AR would provide were not met.

We found similar pre- and post-deployment responses in Oura (Figure 4). Respondents

tended to score "biodiversity preservation," "food production," and "habitat and refuge" the 360 highest (scored four or above on the 5-point Likert scale) in the pre-deployment phase, meaning that respondents expected the AR to increase the provision of these ecosystem services. Similar responses were provided in the post-deployment phase.

Oura respondents most often noted that the AR is preserving biodiversity (option use and non-use values). A Wilcoxon test showed that the median score for five of the seven ecosystem services was not significantly different between pre- and post-deployment (p-value $>0.05$ ) 366 (Table 4).

By measuring differences in the median perception of ecosystem service and additional

368 function provision pre- and post-AR deployment, we were able to make inferences about 369 respondents' perceived usefulness of the deployed ARs. It was also important to determine if, in 
370 general, fishermen perceived the ARs as useful or not.

371 The results indicate that the null hypothesis $\left(\mathrm{H}_{0}\right)$ can be accepted regarding six of the

372 ecosystem services and additional functions in the case of the Nazare AR and five in the case of

373 the Oura AR (Table 4). $\mathrm{H}_{1}$ can be accepted for the option use of "biodiversity preservation" in

374 the case of the Oura AR. The additional function of "diversion effect" was better considered in

375 the Nazare AR than in the Oura AR, where in the latter case it was considered as the worst

376 additional AR function provided. This may suggest some congestion problems perceived by

377 local fishermen (mostly from the port of Quarteira) that benefited from previous AR experience.

378 Respondents in both case studies indicated three ecosystem services that triggered

379 beneficial expectations ("food production", "habitat and refuge" and "biodiversity

380 preservation"). A positive trend was only statistically corroborated for the third ecosystem

381 service, thus found for Oura after AR deployment.

382

383 5. Discussion

384 5.1. Artificial reef perceptions pre- and post-deployment

385 Given that benefits of ARs are often only realized in the distant future, it is not easy for

386 fishermen to conceptualize pre-deployment what ecosystem services an AR is likely to provide

387 or increase unless they have previous experience realizing benefits from ARs or other knowledge

388 of ecosystem service benefits associated with ARs. In order to believe in the potential of ARs to

389 provide future benefits, stakeholders will likely need help understanding the benefits of ARs. By

390 providing credible information in advance to support what ecosystem services they can expect

391 from the deployment of an AR, stakeholders may be more likely to support AR deployment

392 (McGlade, 1999). AR proponents need to show fishermen and potential funders how ARs may 
393 help to protect fish from intensive fisheries, where they can be deployed, as well as showcase

394 that ARs can provide useful services with some degree of tangibility. AR proponents can also

395 focus on how ARs can be used as an effective fisheries management measure. In the case studies

396 presented here, fishermen who were most likely to use the Oura AR seemed to have benefited

397 from previous experience using ARs that had been deployed nearby. That was not the case for

398 fishermen that were likely to fish around the Nazaré AR, where most had not had the opportunity

399 to benefit from such structures previously. This suggests why comparatively Nazaré skippers

400 were slightly more optimistic than those from Quarteira about the future usefulness of the AR

401 pre-deployment.

402

Stakeholders may also have improved perceptions of AR usefulness if the benefits are

403 well-explained pre-deployment; however, unless there are known benefits from an existing AR

404 that can be used as an example, it may be difficult for stakeholders and potential funders to fully

405 believe in the potential usefulness of ARs. On the contrary, if stakeholders' expect that an AR

406 will provide positive benefits and then start accruing benefits from the moment they are able to

407 first use it, support for the AR will be high and can be used as an example in the future to 408 advocate for additional AR deployment (Santos and Monteiro, 2007; Kirkbride-Smith et al., 409 2013).

410 However, even when ARs are already put in place and information is provided, additional

411 support may be needed. For example, divers may easily see and attest to increased biodiversity at

412 a dive site, but other stakeholders, such as fishermen, may not directly perceive that they are also

413 benefiting. Ultimately, fishermen must develop some degree of belief that they have realized

414 ecosystem service benefits in order to ultimately believe that the AR is worthwhile. This was

415 exhibited by Pitcher and Seaman (2000) as the Petrarch's Principle. 
$417 \quad$ 5.2. Reef location profiles and the sense of usefulness

418 In the Nazaré AR case, fishermen had high expectations for what additional ecosystem

419 services and functions the AR could provide from the beginning. However, after the AR was

420 deployed, fishermen believed that they had realized very few ecosystem services and additional

421 functions compared to their pre-deployment expectations. Overall, the results showed that

422 although Nazaré fishermen were optimistic about the capacity of the AR to provide numerous

423 ecosystem services and additional functions, ultimately the AR did not meet fishermen's

424 expectations. The presence of a canyon nearby may influence fishermen to have different views

425 of AR practicality as fishermen will have better access to both shallow and deeper water fish 426 species.

427 In the Oura AR case, however, fishermen's expectations before the AR was deployed 428 were on average lower than the Nazaré fishermen expected. Fishermen on average had high 429 expectations for a much smaller set of ecosystem services, namely "biodiversity preservation", 430 "food production" and as a "habitat and refuge". Fishermen's expectations for this smaller set of 431 ecosystem services were ultimately realized in the post-deployment phase. The fishermen's 432 experience of utilizing other ARs nearby may be related to this sense of practicality.

434 5.3. Cross-checking stakeholders' experience with justifying adequate use of public funds When public funds are invested in deploying ARs, the direct beneficiaries (e.g., 436 fishermen or other operational stakeholders) create expectations for what benefits they will 437 receive. If those expectations are met post-deployment, AR proponents can argue that 438 deployment was a useful allocation of public money. However, negative experiences where high 
439 expectations are not fully met, like the experience of the Nazare AR, can result in increased

440 scrutiny and can result in reluctance to fund AR projects in the future (Schuhmann, 2012).

441

442 5.4. Ecosystem services provided by AR and their differentiation

443 The provision of ecosystem services depends upon complex interactions between

444 organisms and the environment. The need for and importance of individual ecosystem services

445 will depend on the stakeholders that will ultimately be benefiting from them. These factors will

446 therefore affect which ecosystem services are provided, as well as individual stakeholder

447 perceptions of their usefulness. In addition, AR proponents can disseminate information about

448 the likely ecosystem services an AR will provide to potential users. The use of scientific studies,

449 such as the present study, can be used to inform and support future debates on AR usefulness and

450 ultimately improve decision making (Fisher et al., 2009). For example, by showing concrete

451 examples where the deployment of ARs has benefited catch potential by protecting juvenile fish

452 from intensive fisheries, fishermen may better understand the potential benefits a new AR may

453 provide them. For less obvious ecosystem services that are not directly related to catch potential,

454 such as "nutrient cycling", it may be more difficult to provide concrete examples of other

455 ecosystem services; however, it is important to develop ways to collect concrete information on

456 the actual benefits that fishermen have realized from ARs for use in future AR proposals.

457 In the present study, fishermen did not assign high scores to the same AR ecosystem

458 services and additional functions both before and after AR deployment. For the Nazare AR, there

459 were no nearby ARs that could be pointed to as examples. As a result stakeholder expectations

460 were not based on previous experience. On the other hand, for the Oura AR, the pre-and post-

461 deployment results regarding ecosystem service provision were similar. This was likely due to 
462 the fact that most fishermen already had experienced on the use of ARs pre-deployment, and

463 already had a good idea of their usefulness (Ramos and Santos, 2015).

464 Although not tracked, there is a possibility that some of the respondents were queried

465 both before and after deployment. However, since the interviews conducted for this study were

466 anonymous, we cannot confirm which respondents were queried twice. Although this limits

467 further statistical analysis, interviews with the same respondent pool in both the pre- and post-

468 deployment data collections were not possible given the 14 years between studies. Despite this

469 limitation, this study shows that, generally, fishermen across both case studies had a range of

470 expectations of the ecosystem services and benefits that ARs will provide. Likewise, they

471 reported having benefited to some extent from a range of ecosystem services post-deployment.

472 We argue that even if fishermen scored each ecosystem service the same or less post-AR

473 deployment, the ARs are not necessarily deficient in providing ecosystem services. This result

474 likely only indicates that the initial expectations were not completely met and likely unrealistic.

475 A key objective of the present study was to determine if fishermen generally perceived

476 that ARs do not provide additional ecosystem services and functions (in case of similar scores

477 post-deployment compared to pre-deployment $-\mathrm{H}_{0}$ ); or if they actually are providing additional

478 ecosystem services and functions (in case of different scores post-deployment compared to pre-

479 deployment $-\mathrm{H}_{1}$ ). Ultimately, for the two cases presented here, it appears that respondents

480 received positive benefits from ecosystem services provided by ARs in both study areas, but

481 expectations were not met for most of the AR ecosystems services presented to respondents.

483 6. Conclusion

484 Promoters of AR deployment are often motivated by potential benefits of the structures to 
485 human activities. However, apart from a number of studies that have showed positive effects of 486 reef structures in terms of species enhancement, few studies have documented additional 487 ecosystem services that ARs can provide. Even fewer studies have compared pre-deployment 488 perceptions of potential AR ecosystem services and additional functions with those that 489 stakeholders ultimately realize post-deployment. The reason for this may be due to the relatively 490 long delay between when ARs are deployed and when ecosystem services and benefits are 491 realized. ecosystem services and functions that ARs have provided to fisheries stakeholders in Portugal. Unless long-term scientific monitoring is planned in advance, it is very unlikely that funds will be available for a pre-deployment assessment and post-deployment monitoring and evaluation such as that presented here. We argue that funds and future research should focus on similar preand post-AR deployment case studies in order to continue adding to this body of knowledge.

Similarly, AR monitoring and evaluation studies should evaluate potential negative impacts that may be related to AR deployment. Expanded documentation of the effects of AR deployment

500 will provide valuable information that can be used to argue for or against AR deployment in the 501 future.

\section{Acknowledgements}

The authors would like to thank the anonymous reviewers of this journal for helpful 505 comments on an early version of this article. The authors would also like to express their gratitude to all respondents from Quarteira and Nazaré for their participation in either the preand post-deployment phases of the project. We would also like to thank C. Maurício and J. 
508 Delgado as the Nazaré fishing community representatives and H. Rita and Á. Bota from

509 Quarteira fisheries association (Quarpesca), who facilitated the process to collect the data from

510 fishermen.

511

\section{References}

513 Allemand, D., Debernardi E., Seaman W. (2000). Artificial Reefs in the Principality of Monaco:

514 Protection and Enhancement of Coastal Zones. In A. C. Jensen, K. J. Collins, and A. P. M.

515 Lockwood (Eds.), Artificial Reefs in European Seas, Kluwer Academic Publishing, pp. 151$516 \quad 166$

517 Allen, I. E., \& Seaman, C. A. (2007). Likert scales and data analyses. Quality Progress, 40(7), $518 \quad 64-65$.

519 Bell, M., Moore, C. J., \& Murphey, S. W. (1989). Utilization of manufactured reef structures in 520 South Carolina's marine artificial reef program. Bulletin of Marine Science, 44(2), 818-830.

521 Bleck, M., Oumeraci H. (2001). Wave Damping and Spectral Evolution at Artificial Reefs. 522 Proceedings (WAVES, 2001), ASCE, San Francisco, USA, Vol. II, pp. 1062-1071.

523 Bohnsack, J. A. (1996). Maintenance and recovery of reef fishery productivity. In Reef fisheries 524 (pp. 283-313). Springer Netherlands.

525 Bohnsack, J. A., \& Sutherland, D. L. (1985). Artificial reef research: a review with 526 recommendations for future priorities. Bulletin of Marine Science, 37(1), 11-39.

527 Bortone, S. A. (2006). A perspective of artificial reef research: the past, present, and future. 528 Bulletin of Marine Science, 78(1), 1-8. 
529 Brickhill, M. J., Lee, S. Y., \& Connolly, R. M. (2005). Fishes associated with artificial reefs:

530 attributing changes to attraction or production using novel approaches. Journal of Fish

531 Biology, 67(sB), 53-71.

532 Brownell, E. (2011). Negotiating the new economic order of waste. Environmental History, $53316(2), 262-289$.

534 Busch, M., La Notte, A., Laporte, V., \& Erhard, M. (2012). Potentials of quantitative and 535 qualitative approaches to assessing ecosystem services. Ecological indicators, 21, 89-103.

536 CFR, 2016. Fishing Fleet Register. Fleet register on the net. Available from 537 http://ec.europa.eu/fisheries/fleet/index.cfm.

538 Chan, K. M., Guerry, A. D., Balvanera, P., Klain, S., Satterfield, T., Basurto, X., Bostrom, A.

539 Chuenpagdee, R., Gould, R., Halpern, B. S., Hannahs, N., Levine, J., Norton, B., 540 Ruckelshaus, M., Russell, R., Tam, J., \& Woodside, U.. (2012). Where are cultural and social 541 in ecosystem services? A framework for constructive engagement. BioScience, 62(8), 744542756.

543 Charbonnel, E., Serre, C., Ruitton, S., Harmelin, J. G., \& Jensen, A. (2002). Effects of increased 544 habitat complexity on fish assemblages associated with large artificial reef units (French 545 Mediterranean coast). ICES Journal of Marine Science: Journal du Conseil, 59(suppl), S208$546 \quad$ S213.

547 Chen, J. L., Chuang, C. T., Jan, R. Q., Liu, L. C., \& Jan, M. S. (2013). Recreational benefits of 548 ecosystem services on and around artificial reefs: a case study in Penghu, Taiwan. Ocean \& 549 Coastal Management, 85, 58-64. 
550 Chojnacki, J.C. (2000). Experimental effects of artificial reefs in the southern Baltic

551 (Pomeranian Bay). In A. C. Jensen, K. J. Collins, and A. P. M. Lockwood (Eds.), Artificial

552 Reefs in European Seas, Kluwer Academic Publishing, Dordrecht, pp. 307-317.

553 Clark, S., Edwards, A.J. (1999). An evaluation of artificial reef structures as tools for marine 554 habitat rehabilitation in the Maldives. Aquatic Conservation: Marine and Freshwater $555 \quad$ Ecosystems 9: 5-21.

556 Clauss, G.F., Habel, R. (2000). Artificial reefs for coastal protection-transient viscous 557 computation and experimental evaluation. 27th International Conference on Coastal 558 Engineering, Sydney, Australia, pp. 1-14.

559 Costanza, R., d'Arge, R., de Groot, R., Farber, S., Grasso, M., Hannon, B., Limburg, K., Naeem, 560 S., O'Neill, R. V., Paruelo, J., Raskin, R. G., Sutton, P. \& van den Belt, M. (1997). The value 561 of the world's ecosystem services and natural capital. Nature, 387, 253-260.

562 Costanza, R., de Groot, R., Sutton, P., van der Ploeg, S., Anderson, S. J., Kubiszewski, I., Farber, 563 S. \& Turner, R. K. (2014). Changes in the global value of ecosystem services. Global 564 Environmental Change, 26, 152-158.

565 Dawes, J. G. (2008). Do data characteristics change according to the number of scale points 566 used? An experiment using 5 point, 7 point and 10 point scales. International Journal of $567 \quad$ Market Research, 51(1).

568 De Groot, R., Brander, L., Van Der Ploeg, S., Costanza, R., Bernard, F., Braat, L., Christie, M., 569 Crossman, N., Ghermandi, A., Hein, L., Hussain, S., Kumar, P., McVittie, A., Portela, R., 570 Rodriguez, L. C., ten Brink, P., \& van Beukering, P. (2012). Global estimates of the value of 571 ecosystems and their services in monetary units. Ecosystem Services, 1(1), 50-61. 
572 Ding, Y., Yeh, K. C., Chen, H. K., \& Wang, S. S. (2013). Coastal and Estuarine planning for

573 flood and erosion protection using integrated coastal model. Coastal Hazards, (2), 163.

574 Ditton, R. B., Osburn, H. R., Baker, T. L., \& Thailing, C. E. (2002). Demographics, attitudes,

575 and reef management preferences of sport divers in offshore Texas waters. ICES Journal of

576 Marine Science: Journal du Conseil, 59(suppl), S186-S191.

577 Doyle, M. W., \& Havlick, D. G. (2009). Infrastructure and the environment. Annual Review of $578 \quad$ Environment and Resources, 34, 349-373.

579 Edwards, A. J., \& Gomez, E. D. (2007). Reef restoration concepts and guidelines: making 580 sensible management choices in the face of uncertainty. Capacity Building for Management 581 Programme/Coral Reef Targeted Research: St. Lucia. ISBN 1-921317-00-2. 38 pp.

582 Einbinder, S., Perelberg, A., Ben-Shaprut, O., Foucart, M.H., Shashar, N. (2006). Effects of 583 artificial reefs on fish grazing in their vicinity: Evidence from algae presentation experiments.

$584 \quad$ Marine Environmental Research 61: 110-119.

585 Falcão, M., Santos, M. N., Vicente, M., \& Monteiro, C. C. (2007). Biogeochemical processes 586 and nutrient cycling within an artificial reef off Southern Portugal. Marine Environmental $587 \quad$ Research, 63(5), 429-444.

588 Fisher, B., Turner, R. K., \& Morling, P. (2009). Defining and classifying ecosystem services for 589 decision making. Ecological Economics, 68(3), 643-653.

590 Fletcher, S., Bateman, P., \& Emery, A. (2011). The governance of the Boscombe artificial surf $591 \quad$ reef, UK. Land Use Policy, 28(2), 395-401.

592 Ford, J. R., \& Swearer, S. E. (2013). Two's company, three's a crowd: Food and shelter limitation 593 outweigh the benefits of group living in a shoaling fish. Ecology, 94(5), 1069-1077. 
594 Gallaway, B.J., Cole, J.G., Meyer, R., Roscigno, P. (1999). Delineation of Essential Habitat for

595 Juvenile Red Snapper in the Northwestern Gulf of Mexico. Transactions of the American $596 \quad$ Fisheries Society, 128(4): 713-726.

597 Goklany, I. M. (2009). Technological Substitution and Augmentation of Ecosystem Services. 598 The Princeton Guide to Ecology, 659-69.

599 Goudas, C., \& Katsiaris, G. (Eds.). (2003). Soft Shore Protection: An Environmental Innovation 600 in Coastal Engineering (Vol. 7). Springer, Dordrecht.

601 Goulder, L. H., \& Kennedy, D. (2011). Interpreting and estimating the value of ecosystem 602 services, in P. Kareiva et al. (eds), Natural capital: theory and practice of mapping ecosystem 603 services, Oxford, Oxford University Press. 34-53.

$604 \mathrm{Gu}, \mathrm{R}$. R. (2005). Beneficial reuses of scrap tires in hydraulic engineering. In Water Pollution 605 (pp. 183-215). Springer Berlin, Heidelberg.

606 Hackett, S., \& Dissanayake, S. T. (2014). Environmental and natural resources economics: 607 Theory, policy, and the sustainable society. Routledge.

608 Himes, A. H. (2007). Performance indicators in MPA management: using questionnaires to 609 analyze stakeholder preferences. Ocean \& Coastal Management, 50(5), 329-351.

610 Huth, W. L., \& Morgan, O. A. (2011). Measuring the willingness to pay for Cave Diving. 611 Marine Resource Economics, 26(2), 151-166.

612 Jacobus, J., \& W Webb, P. (2005). Using fish distributions and behavior in patchy habitats to 613 evaluate potential effects of fragmentation on small marsh fishes: a case study. Journal of $614 \quad$ Great Lakes Research, 31, 197-211.

615 Johns, G., Kelble, C., Lee, D., Leeworthy, V. R., \& Nuttle, W. K. (2013). Ecosystem services 616 provided by the South Florida coastal marine ecosystem. MARES White Paper (20 April 2013 
617 version. Available from: https://nccospublicstor.blob.core.windows.net/projects618 attachments/200/MARES_White\%20Paper_Ecosystem\%20Services.pdf

619 Kirkbride-Smith, A. E., Wheeler, P. M., \& Johnson, M. L. (2013). The Relationship between 620 Diver Experience Levels and Perceptions of Attractiveness of Artificial Reefs-Examination of 621 a Potential Management Tool. PloS one, 8(7), e68899.

622 Kurien, J. (2003). The blessing of the commons: small-scale fisheries, community property rights 623 and coastal natural assets. Working Paper 349. Center for Development Studies, 624 Thiruvananthapuram, India.

625 Lamarque, P., Tappeiner, U., Turner, C., Steinbacher, M., Bardgett, R. D., Szukics, U., ... \& 626 Lavorel, S. (2011). Stakeholder perceptions of grassland ecosystem services in relation to 627 knowledge on soil fertility and biodiversity. Regional environmental change, 11(4), 791-804.

628 Lamberti, A., \& Zanuttigh, B. (2005). An integrated approach to beach management in Lido di 629 Dante, Italy. Estuarine, Coastal and Shelf Science, 62(3), 441-451.

630 Leitão, F., Santos, M. N., Erzini, K., \& Monteiro, C. C. (2009). Diplodus spp. assemblages on 631 artificial reefs: importance for near shore fisheries. Fisheries Management and Ecology, $632 \quad 16(2), 88-99$.

633 Levrel, H., Pioch, S., \& Spieler, R. (2012). Compensatory mitigation in marine ecosystems: 634 Which indicators for assessing the "no net loss" goal of ecosystem services and ecological 635 functions? Marine Policy, 36(6), 1202-1210.

636 Lowry, M. B., Glasby, T. M., Boys, C. A., Folpp, H., Suthers, I., \& Gregson, M. (2014).

637 Response of fish communities to the deployment of estuarine artificial reefs for fisheries 638 enhancement. Fisheries Management and Ecology, 21(1), 42-56. 
639 Lynn, P. A. (2013). Electricity from wave and tide: An introduction to marine energy. John 640 Wiley \& Sons.

641 MacDonald, C.D., Mitsuyasu, C.A., Corbin, E. (1999). A planned underwater dive attractions 642 program for Hawaii. Ocean Resources Branch, State of Hawaii Department of Business, 643 Economic Development and Tourism. Ocean Resources Branch Contribution No. 147, 644 pp.180-187.

645 Marzinelli, E. M., Zagal, C. J., Chapman, M. G., \& Underwood, A. J. (2009). Do modified 646 habitats have direct or indirect effects on epifauna? Ecology, 90(10), 2948-2955.

647 Morang, A., Waters, J. P., \& Stauble, D. K. (2014). Performance of submerged prefabricated 648 structures to improve sand retention at beach nourishment projects. Journal of Coastal 649 Research, 30(6), 1140-1156.

650 Matsuoka, T., Nakashima, T., \& Nagasawa, N. (2005). A review of ghost fishing: scientific 651 approaches to evaluation and solutions. Fisheries Science, 71(4), 691-702.

652 McGlade, J.M. (1999). Ecosystem analysis and the governance of natural resources. In Advanced 653 Ecological Theory. McGlade, J.M., Ed. Blackwell Scientific, Oxford. pp. 309-341.

654 Milon, J.W. (1989). Artificial marine habitat characteristics and participation behavior by sport 655 anglers and divers. Bulletin of Marine Science 44(2): 853-862.

656 Montemayor, J.R. (1991). A review of developments on artificial reefs for fishery enhancement 657 in the Philippines. In: Pietersz, V. L. C. (Ed.), Symposium on Artificial Reefs and Fish 658 Aggregating Devices as Tools for the Management and Enhancement of Marine Fishery 659 Resources, 14-17 May, 1990, Colombo, Sri Lanka. Regional Office for Asia and the Pacific, 660 United Nations Food and Agriculture Organisation, Bangkok, pp. 229-243. 
661 Moura A., Boaventura, D., Cúrdia, J., Santos, M.N., Monteiro, C.C. (2006). Biomass production

662 of early macrobenthic communities at the Faro/Ancão artificial reef (Portugal): effect of depth 663 and reef layer. Bulletin of Marine Science 78(1): 83-92.

664 Moura, A., Boaventura, D., Cúrdia, J., Carvalho, S., Cancela da Fonseca, L., Leitão, F.M., 665 Santos, M.N., Monteiro C.C. (2007). Effect of depth and reef structure on early macrobenthic 666 communities of the Algarve artificial reefs (southern Portugal). Hydrobiologia 580: 173-180.

667 Musa, G., Seng, W. T., Thirumoorthi, T., \& Abessi, M. (2011). The influence of scuba divers' 668 personality, experience, and demographic profile on their underwater behavior. Tourism in 669 Marine Environments, 7(1), 1-14.

670 Ng, K., Phillips, M. R., Calado, H., Borges, P., \& Veloso-Gomes, F. (2013). Seeking harmony in 671 coastal development for small islands: Exploring multifunctional artificial reefs for São 672 Miguel Island, the Azores. Applied Geography, 44, 99-111.

673 Nicoletti, L., Marzialetti, S., Paganelli, D., \& Ardizzone, G. D. (2007). Long-term changes in a 674 benthic assemblage associated with artificial reefs. In Biodiversity in Enclosed Seas and 675 Artificial Marine Habitats (pp. 233-240). Springer, Dordrecht, Netherlands.

676 Oh, C. O., Ditton, R. B., \& Stoll, J. R. (2008). The economic value of scuba-diving use of natural 677 and artificial reef habitats. Society and Natural Resources, 21(6), 455-468.

678 Oliveira, M. T., Ramos, J., \& Santos, M. N. (2015). An approach to the economic value of diving 679 sites: artificial versus natural reefs off Sal Island, Cape Verde. Journal of Applied $680 \quad$ Ichthyology, 31(S3), 86-95.

681 Perkol-Finkel, S., \& Benayahu, Y. (2005). Recruitment of benthic organisms onto a planned 682 artificial reef: shifts in community structure one decade post-deployment. Marine 683 Environmental Research, 59(2), 79-99. 
684 Pilkey, O. H., \& Cooper, J. A. G. (2012). “Alternative” Shoreline Erosion Control Devices: A 685 Review. In Pitfalls of Shoreline Stabilization (pp. 187-214). Springer, Dordrecht, Netherlands. 686 Pitcher, T.J., \& Seaman Jr., W. (2000). Petrarch's Principle: how protected human-made reefs 687 can help the reconstruction of fisheries and marine ecosystems. Fish and Fisheries 1: 73-81.

688 Polak, O., \& Shashar, N. (2012). Can a small artificial reef reduce diving pressure from a natural 689 coral reef? Lessons learned from Eilat, Red Sea. Ocean \& Coastal Management, 55, 94-100.

690 Pratt, T. C., Smokorowski, K. E., \& Muirhead, J. R. (2005). Development and experimental 691 assessment of an underwater video technique for assessing fish-habitat relationships. Archiv 692 für Hydrobiologie, 164(4), 547-571.

693

694 R Development Core Team (2015). R version 3.1.3 (2015-03-09) -- "Smooth Sidewalk". R: A 695 language and environment for statistical computing. R Foundation for Statistical Computing, 696 Vienna, Austria. ISBN 3-900051-07-0. Available at: http://www.R-project.org.

697 Ramos, J., \& Santos, M. N. (2015). Facilitating fishing decisions in an artificial reef area off 698 southern Portugal: a case study using generalized additive models. Journal of Applied 699 Ichthyology, 31(S3), 24-34.

700 Ramos, J., Santos, M. N., Whitmarsh, D., \& Monteiro, C. C. (2011a). Stakeholder analysis in the 701 Portuguese artificial reef context: winners and losers. Brazilian Journal of Oceanography, 702 59(SPE1), 133-143.

703 Ramos, J., Oliveira, M. T., \& Santos, M. N. (2011b). Stakeholder perceptions of decision704 making process on marine biodiversity conservation on Sal island (Cape Verde). Brazilian 705 Journal of Oceanography, 59(SPE1), 95-105. 
706 Ramos, J., Santos, M. N., Whitmarsh, D., \& Monteiro, C. C. (2006). The usefulness of the

707 analytic hierarchy process for understanding reef diving choices: a case study. Bulletin of

708 Marine Science, 78(1), 213-219.

709 Ramos, J. H. P. (2007). Socio-economic implications of artificial reef deployment: a Portuguese

710 case study (Doctoral dissertation, Department of Economics, University of Portsmouth).

711 Relini, G., Relini, M., Palandri, G., Merello, S., Beccornia, E. (2007). History, ecology and

712 trends for artificial reefs of the Ligurian Sea, Italy. Hydrobiologia 580(1): 193-217.

713 Rendle, E. J., \& Rodwell, L. D. (2014). Artificial surf reefs: A preliminary assessment of the

714 potential to enhance a coastal economy. Marine Policy, 45, 349-358.

715 Santos, L. N., Araújo, F. G., \& Brotto, D. S. (2008). Artificial structures as tools for fish habitat

716 rehabilitation in a neotropical reservoir. Aquatic conservation: marine and freshwater

717 ecosystems, 18(6), 896-908.

718 Santos, M. N., Monteiro, C. C., \& Lassèrre, G. (1996). Finfish attraction and fisheries

719 enhancement on artificial reefs: a review. In European artificial reef research. Proceedings of

720 the 1st EARRN conference, Ancona, Italy (pp. 97-114).

721 Santos, M. N., \& Monteiro, C. C. (1997). The Olhao artificial reef system (south Portugal): fish

722 assemblages and fishing yield. Fisheries Research, 30(1-2), 33-41.

723 Santos, M. N., \& Monteiro, C. C. (1998). Comparison of the catch and fishing yield from an

724 artificial reef system and neighbouring areas off Faro (Algarve, south Portugal). Fisheries

$725 \quad$ Research, 39(1), 55-65.

726 Santos, M.N., Monteiro, C.C. (2007). A fourteen-year overview of the fish assemblages and

727 yield of the two oldest Algarve artificial reefs (southern Portugal). Hydrobiologia 580: 225-

728231. 
729 Santos M.N., Monteiro C.C., Leitão F. (2011). The role of artificial reefs on the sustainability of

730 artisanal fisheries in the Algarve coastal waters (Southern Portugal). In Artificial reefs in

731 Fisheries Management, S.Bortone, F.P. Brandini, G. Fabi and S. Otake (Editors), CRC Press,

732 Taylor \& Francis Group, Boca Raton, Chap. 14: 221-237.

733 Sawyer, J. F. (2001). Shipbreaking and the North-South debate: economic development or

734 environmental and labor catastrophe. Penn State International Law Review, 20, 535.

735 Schmidt, K., Walz, A., Martín-López, B., \& Sachse, R. (2017). Testing socio-cultural valuation

736 methods of ecosystem services to explain land use preferences. Ecosystem Services, 26, 270-

737288.

738 Schuhmann, P. W. (2012). The valuation of marine ecosystem goods and services in the wider

739 Caribbean region. Center for Resource Management and Environmental Studies, University

740 of the West Indies, Cave Hill Campus, Barbados, CERMES Technical Report, (63), 57.

741 Seaman, W. (2007). Artificial habitats and the restoration of degraded marine ecosystems and

742 fisheries. Hydrobiologia, 580(1), 143-155.

743 Shipp, R.L. (1999). The artificial reef debate: are we asking the right questions? Gulf of Mexico

744 Science 17: 51-55.

745 Simberloff, D., Von Holle, B. (1999). Positive interactions of non-indigenous species: invasional

746 meltdown? Biological Invasions 1: 21-32.

747 Simon, T., Pinheiro, H. T., \& Joyeux, J. C. (2011). Target fishes on artificial reefs: Evidences of

748 impacts over nearby natural environments. Science of the Total Environment, 409(21), 4579-

7494584. 
750 Smith, N. S. (2010). Lionfish invasion in nearshore waters of the Bahamas: an examination of

751 the effects of artificial structures and invader versus native species colonization rates.

752 Doctoral dissertation, Department of Zoology, University of British Columbia.

753 Sosa-López, A., Mouillot, D., Do Chi, T., \& Ramos-Miranda, J. (2005). Ecological indicators

754 based on fish biomass distribution along trophic levels: an application to the Terminos coastal

755 lagoon, Mexico. ICES Journal of Marine Science: Journal du Conseil, 62(3), 453-458.

756 Sterner, T. (2003). Policy instruments for environmental and natural resource management.

757 Resources for the Future, RFF Press, Washington, DC..

758 Sutton, S. G., \& Bushnell, S. L. (2007). Socio-economic aspects of artificial reefs:

759 Considerations for the Great Barrier Reef Marine Park. Ocean \& Coastal Management,

$760 \quad 50(10), 829-846$.

761 Ten Voorde, M., do Carmo, J. A., \& Neves, M. G. (2009). Designing a preliminary

762 multifunctional artificial reef to protect the Portuguese coast. Journal of Coastal Research, $763 \quad 69-79$.

764 Tunca, S., Miran, B., \& Ünal, V. (2012). Decisions of stakeholders for the proposed artificial 765 reef deployment: Analytic hierarchy process approach. Su Ürünleri Dergisi, 29(1).

766 Tyler, P. , Amaro, T., Arzola, R., Cunha, M. R., de Stigter, H., Goodday, A., Huvenne, V.,

767 Ingels, J., Kiriakoulakis, K., Lastras, G., Masson, D., Oliveira, A., Pattenden, A., Vanreusel, 768 A., van Weering, T., Vitorino, J., Witte, U., Wolff, G. (2009). Europe's grand Canyon. 769 Oceanography, 22(1), 46-57.

770 Van Treeck, P., \& Eisinger, M. (2012). Diverting Pressure from Coral Reefs: Artificial

771 Underwater Parks as a Means of Integrating Development and Reef Conservation. New $772 \quad$ Frontiers in Marine Tourism, 153. 
773 Van Treeck, P., Schuhmacher, H. (1999). Mass Diving Tourism - A New Dimension Calls for

774 New Management Approaches. Marine Pollution Bulletin 37(8-12): 499-504.

775 Watanuky N., Gonzales, B.J. (2006). The potential of artificial reefs as fisheries management

776 tools in developing countries. Bulletin of Marine Science 78(1): 9-19.

777 Whitmarsh, D., Santos, M.N., Ramos, J., Monteiro, C.C. (2008). Marine habitat modification off

778 the Algarve (southern Portugal): An economic analysis of the fisheries and the prospects for

779 management. Ocean and Coastal Management 51: 463-468

780 Wilhelmsson, D., Ohman, M.C., Stahl, H., Shlesinger, Y. (1998). Artificial reefs and dive 781 tourism in Eilat, Israel. Ambio 27: 764-766.

782 Williams, T. W. (2006). Sinking Poor Decision-Making with Best Practices: A Case Study of 783 Artificial Reef Decision-Making in the Florida Keys. Virginia Commonwealth University, 784 America.

785 World Resources Institute (2005). Ecosystem and human well-being: wetlands and water 786 synthesis. World Resources Institute, Washington, DC.

787

788 


\section{Table $\mathbf{1}$ (on next page)}

Ecosystem services and additional functions potentially provided by artificial reefs (ARs).

Note: Ecosystem good or service: Provisioning (P), regulating (R), cultural (C), and supporting (S). Source: Based on Millennium Ecosystem Assessment (MEA) (World Resources Institute, 2005). There are two AR effects respondents were asked to consider ("diversion effect "and "reuse of obsolete structures"), however, they are not considered to be ecosystem goods and services. Consequently they should be considered solely as AR functions. For simplicity, the authors have considered additional functions alongside AR ecosystem services, but they are signed with a $(\mathrm{N})$. 
1

\# Ecosystem good/service or Use Description
additional function

1 Food production $(\mathrm{P}) \quad$ Current Direct use (extractive)

2 Recreational (C) Current Direct use (non-extractive)

3 Biological control (R) Current Indirect use

4 Nutrient cycling (S) Current Indirect use

5 Disturbance regulation $(\mathrm{R}) \quad$ Current Indirect use

6 Reuse of obsolete structures (N) Current Indirect use

7 Habitat and refuge (S) Current Indirect use and non use

8 Diversion effect $(\mathrm{N}) \quad$ Current Indirect use

9 Biodiversity preservation (S) Future Option use and non use

2 


\section{Table 2 (on next page)}

5-point Likert scale questions posed to respondents.

Note: Right side column in brackets means ecosystem service (ES) or additional function $(\mathrm{AF})$. 
Pre-deployment: By deploying an AR in (your specific area), do you think that... Post-deployment: After using an AR in (your specific area), do you think that...

The production of fish and other seafood is...

Recreation such as Scuba diving or sea angling is...

The absence of plagues or unwanted organisms is...

Cleaner waters in the area are...

Coast protection against sea storms is...

Reuse of scrap, wreck or obsolete structures is...

Shelter or refuge for young or vulnerable fish is...

Lack of dredging, trawling or other active gear on the area is...

The chance of finding many different organisms in the future is...
Food production (ES)

1. Much less Recreation (ES)

2. Slightly less Biological control (ES)

3. The same Disturbance regulation (ES)

4. Slightly more Reuse of obsolete structures (AF)

5. Much more Habitat and refuge (ES)

Diversion effect (AF)

Biodiversity preservation (ES) 


\section{Table 3 (on next page)}

Number of respondents and usable responses to pre- and post-AR deployment semistructured questionnaire-based interviews. 


\begin{tabular}{lcccc}
\hline & \multicolumn{4}{c}{ Artificial reef phase } \\
\cline { 2 - 5 } Case study site & \multicolumn{2}{c}{ Pre-deployment } & \multicolumn{2}{c}{ Post-deployment } \\
\cline { 2 - 5 } & Participants & $\begin{array}{c}\text { Usable } \\
\text { responses }\end{array}$ & Participants & Usable responses \\
\hline Nazaré & 28 & 23 & 24 & 23 \\
Oura & 30 & 23 & 25 & 23 \\
Total respondents & 58 & 46 & 49 & 46 \\
\hline
\end{tabular}




\section{Table 4 (on next page)}

Results of the Wilcoxon rank sum test with continuity correction (two-tailed test) comparing respondents' perceptions of ecosystem service provision pre- and post-AR deployment.

Notes: Left side column in brackets means ecosystem service (ES) or additional function (AF). $W$ is the sum of the ranks of the observations. Significance level: n.s. - non significant, *$p<0.05, * *-p<0.005$ and ${ }^{* * *}-p<0.0005$. 
1

\begin{tabular}{llllc}
\hline \multirow{2}{*}{ Ecosystem service or additional function } & $\mathbf{W}$ & $\boldsymbol{p}$-value & $\mathbf{W}$ & $\boldsymbol{p}$-value \\
\cline { 2 - 5 } & 308 & $0.2910^{\text {n.s. }}$ & 232 & $0.4141^{\text {n.s. }}$ \\
\hline 1 Food production (ES) & 367.5 & $0.0130^{*}$ & 253.5 & $0.7852^{\text {n.s. }}$ \\
2 Recreation (ES) & 349 & $0.0373^{*}$ & 235 & $0.4720^{\text {n.s. }}$ \\
3 Biological control (ES) & 295 & $0.3409^{\text {n.s. }}$ & 326 & $0.1391^{\text {n.s. }}$ \\
4 Nutrient cycling (ES) & 265.5 & $0.9867^{\text {n.s. }}$ & 382 & $0.0024^{* *}$ \\
5 Disturbance regulation (ES) & 342 & $0.0231^{*}$ & 414.5 & $0.0004^{* * *}$ \\
6 Reuse of obsolete structures (AF) & 268.5 & $0.9295^{\text {n.s. }}$ & 243.5 & $0.6222^{\text {n.s. }}$ \\
7 Habitat and refuge (ES) & 325 & $0.1682^{\text {n.s. }}$ & 354.5 & $0.0245^{*}$ \\
8 Diversion effect (AF) & 264.5 & $1.0000^{\text {n.s. }}$ & 183 & $0.0449^{*}$ \\
9 Biodiversity preservation (ES) & & &
\end{tabular}

2 
Figure 1 (on next page)

Case studies location off Portugal.

A) Nazaré artificial reef (Center region), and B) Oura artificial reef (Algarve region). Depth is represented by the blue lines and the red shapes show the artificial reef placement. 


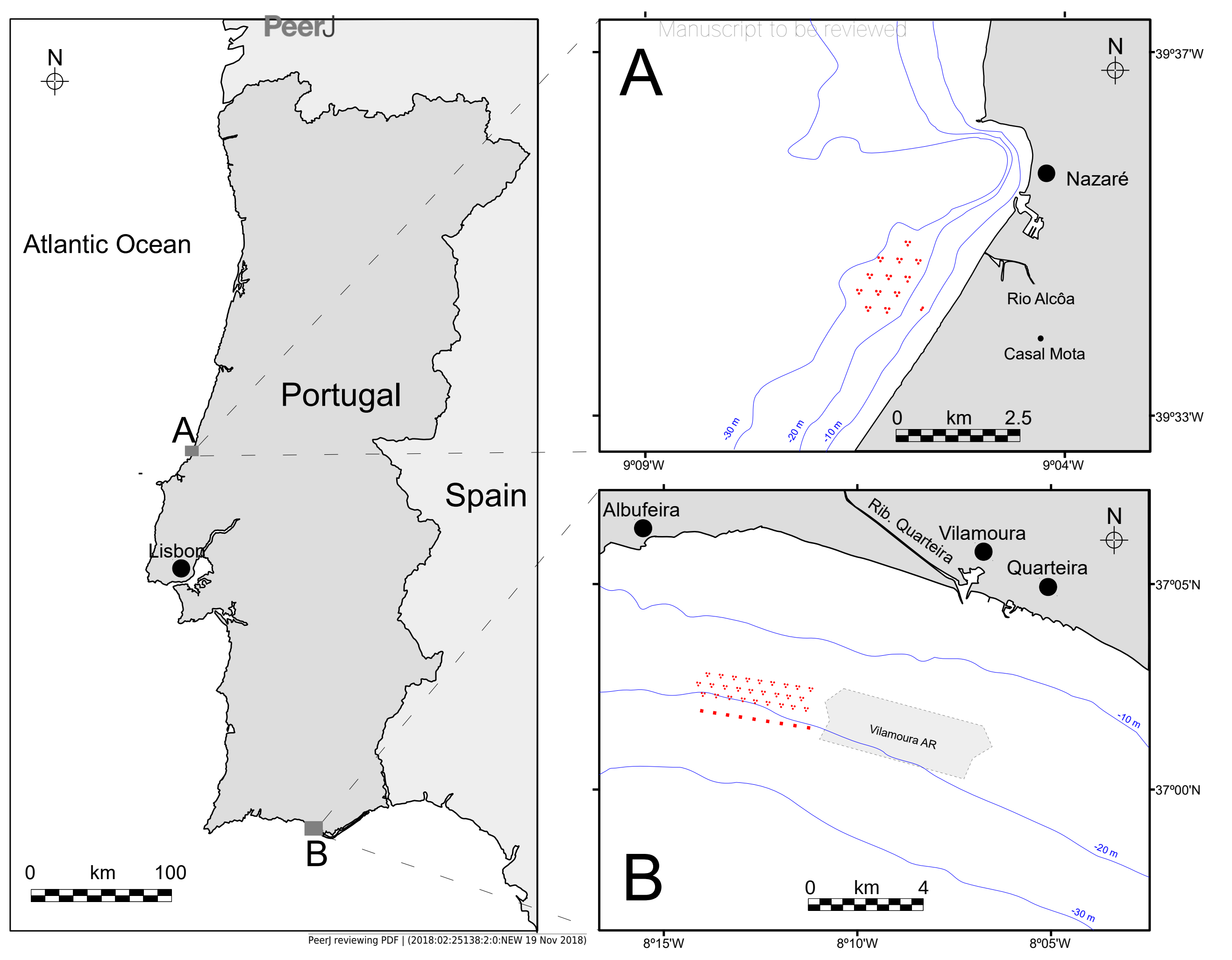


Figure 2 (on next page)

Artificial reef profile and use (not at scale).

$A$ and C) represent pre-AR deployment (Nazaré and Oura, respectively), B and D) represent post-AR deployment (Nazaré and Oura, respectively). 
A
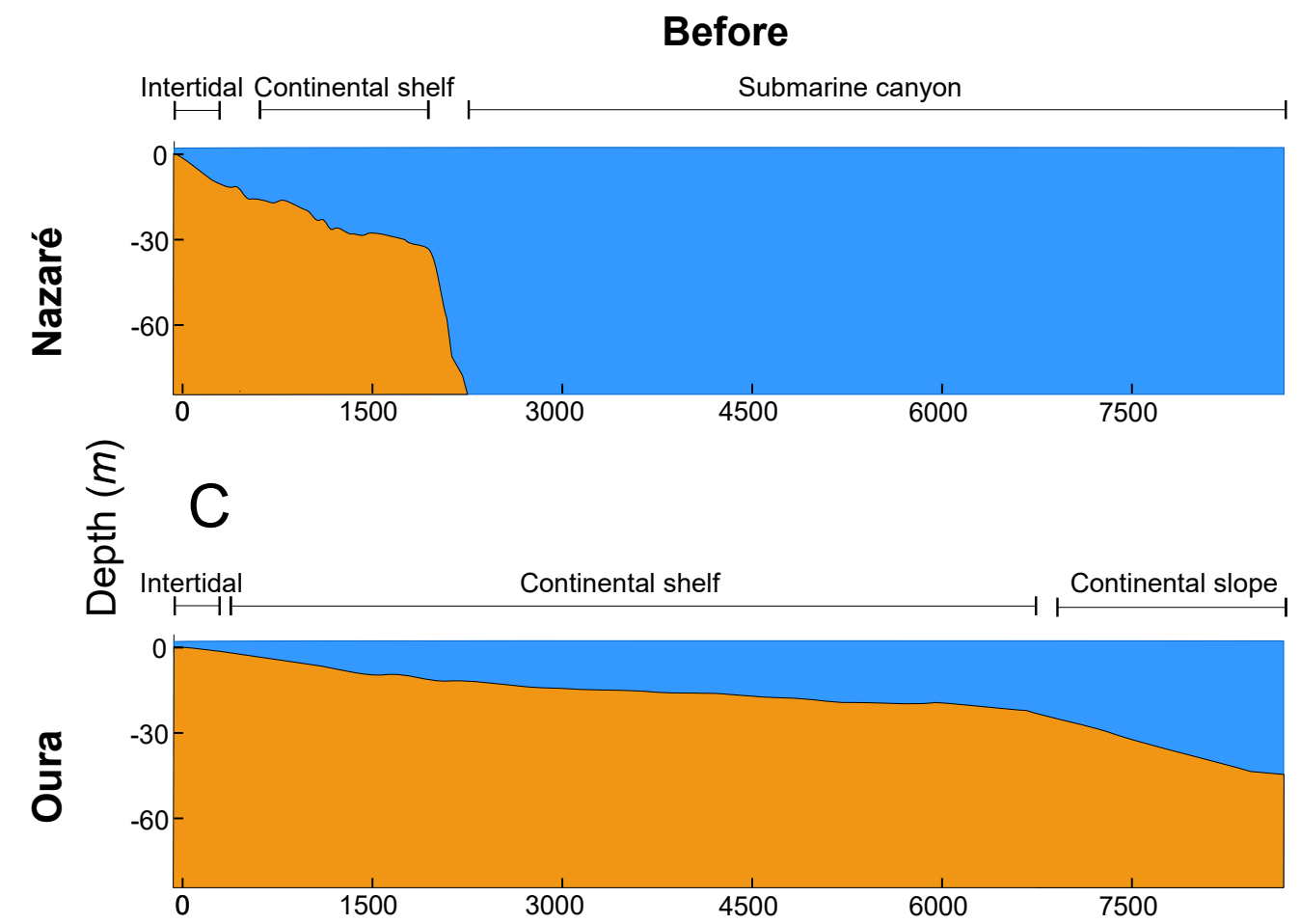

B

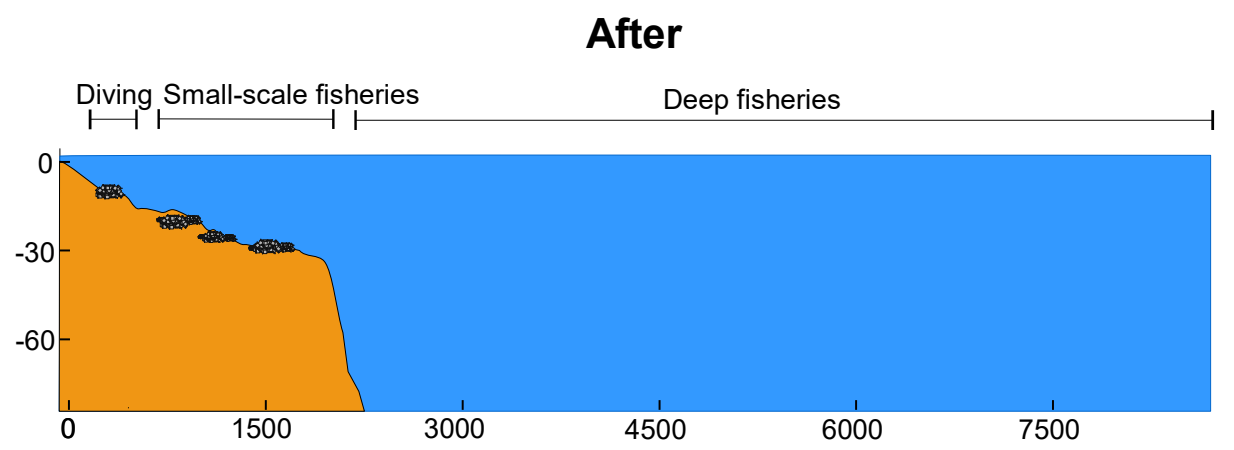

D

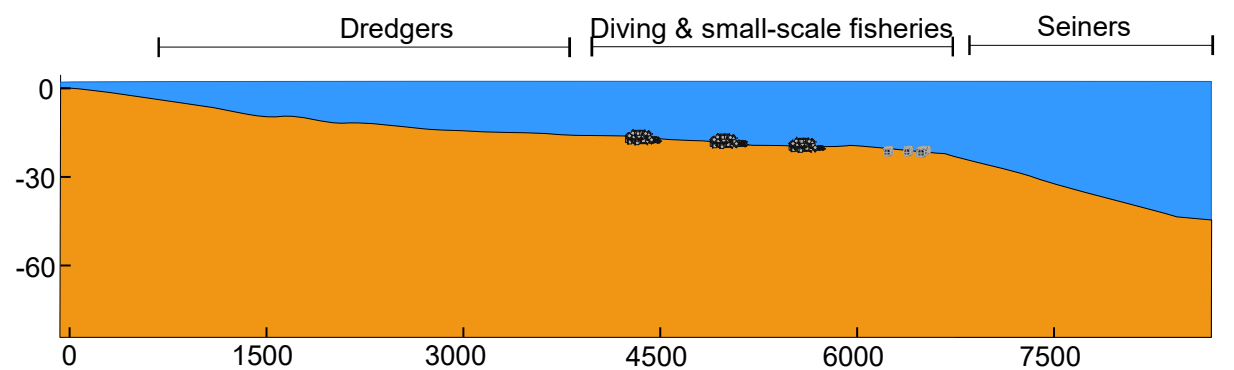


Figure 3

Study design indicating this study's hypotheses regarding fishermen's expectations and perceptions of ecosystem services and additional functions related to AR deployment.

$\mathrm{Q}_{\mathrm{t} 1}$ represents the pre-deployment questionnaire, whereas $\mathrm{Q}_{\mathrm{t} 2}$ represents the postdeployment questionnaire.

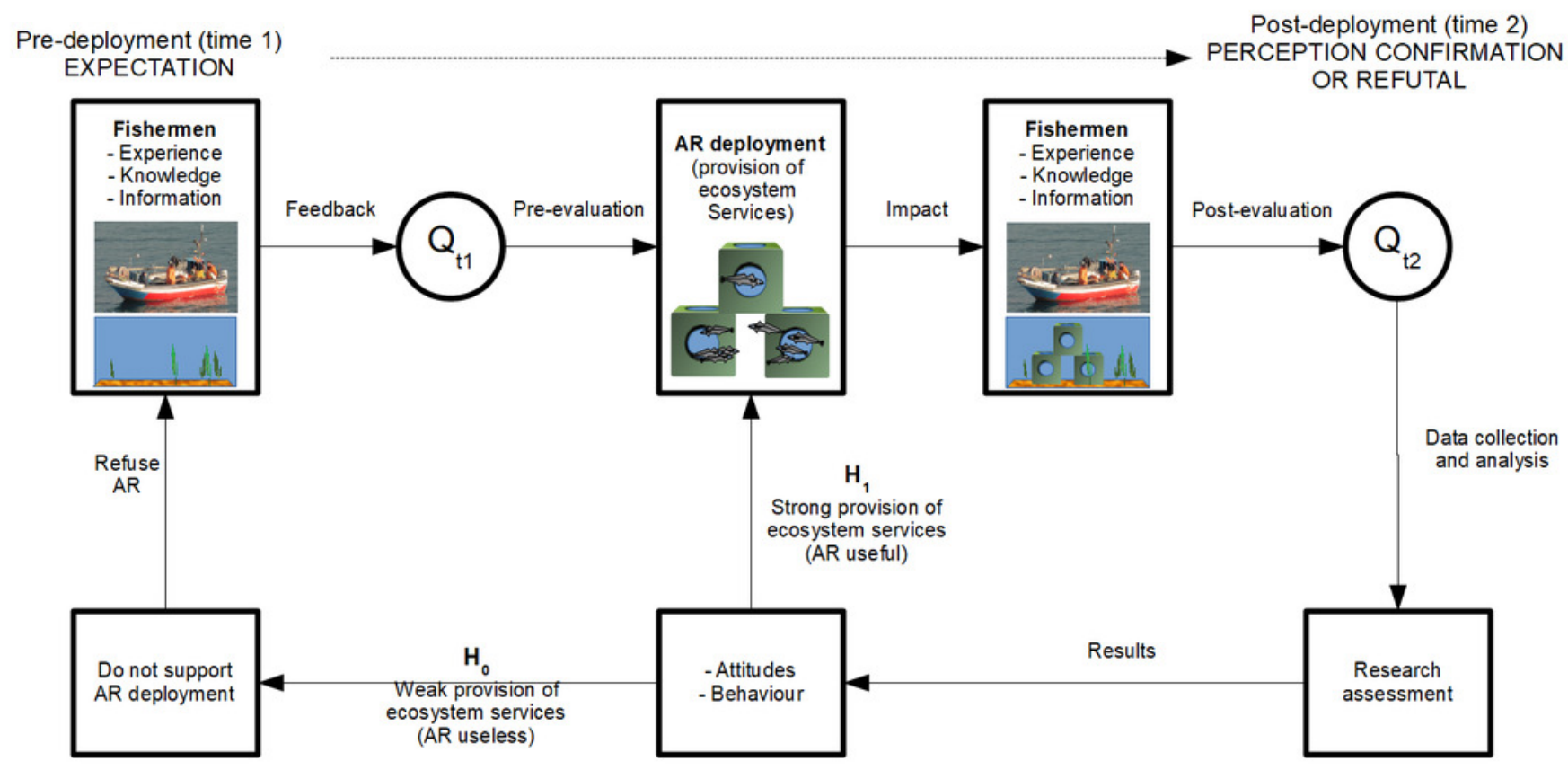




\section{Figure 4 (on next page)}

Bubble plots showing pre- and post-deployment ecosystem service and additional function perceptions found by fishermen on the ARs of Oura and Nazaré (Portugal).

The diameter of each circle and the correspondent figure inside represent the number of respondents' perception of each ecosystem service/additional function. (Significance level: * $-p<0.05, * *-p<0.005$ and $\left.{ }^{* * *}-p<0.0005\right)$. 
PeerJ

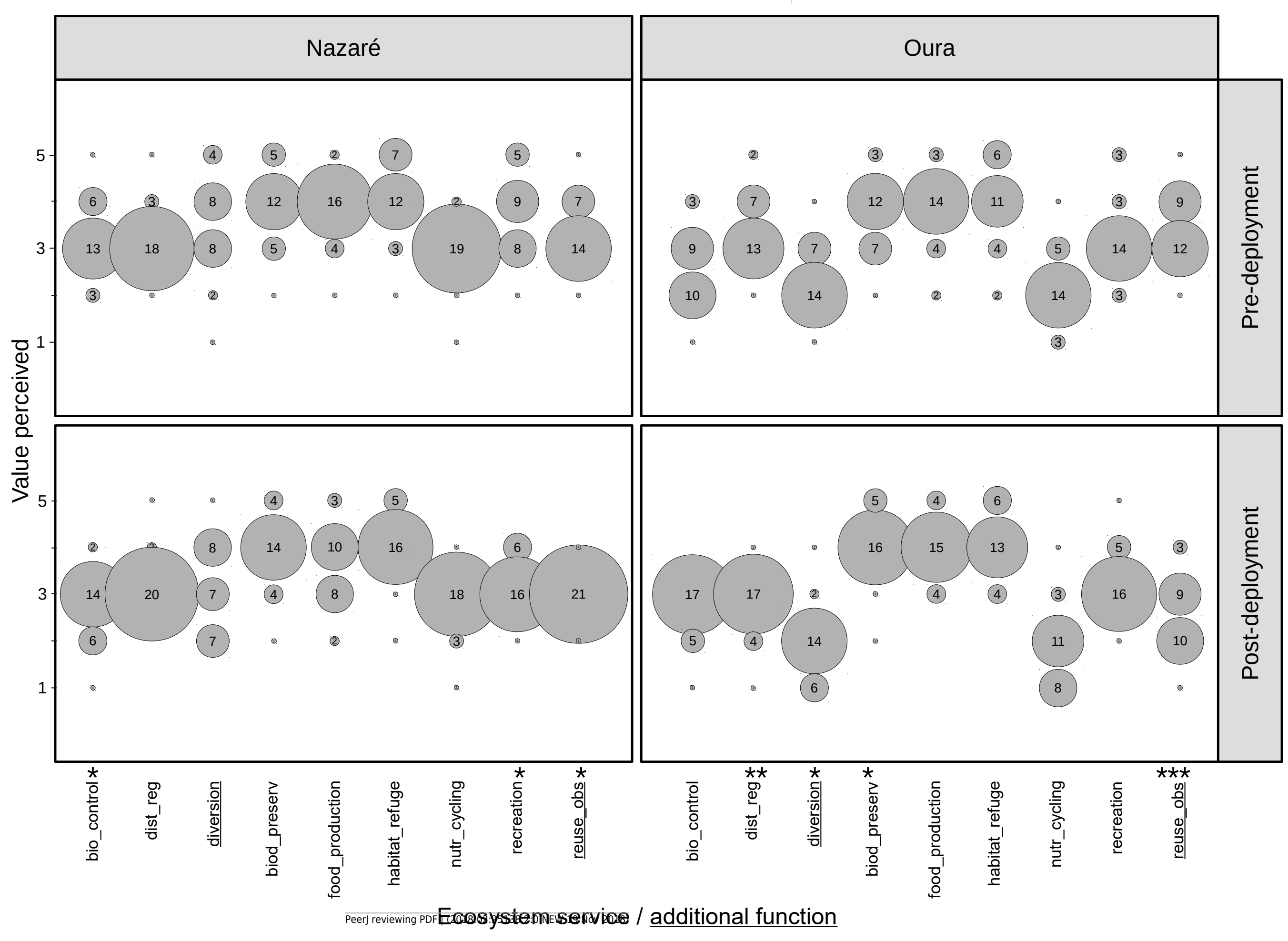

